\title{
Detection of Initiation Activity of 1,2-Dimethylhydrazine in in vivo Medium-Term Liver Initiation Assay System using 4-Week-Old Rats without Hepatocellular Proliferative Stimuli during the Test Chemical Treatment Period
}

\author{
Yoshiji ASAOKA ${ }^{1,2)}$, Hiroki SAKAI ${ }^{1,3) *}$, Akihiro HIRATA ${ }^{4)}$, Jun SASAKI ${ }^{1,5)}$, Masanobu GORYO ${ }^{2,5)}$, \\ Yohei MIYAMOTO $^{2)}$, Tokuma YANAI ${ }^{1,3)}$, Toshiaki MASEGI ${ }^{1,3)}$ and Kosuke OKADA ${ }^{1,5)}$ \\ ${ }^{1)}$ Pathogenetic Veterinary Science, United Graduate School of Veterinary Sciences, ${ }^{3)}$ Laboratory of Veterinary Pathology, Faculty of \\ Applied Biological Sciences and ${ }^{4}$ Division of Animal Experiment, Life Science Research Center, Gifu University, 1-1 Yanagido, Gifu \\ 501-1193, ${ }^{2)}$ Laboratory of Toxicology and Pharmacokinetics, Pharmaceutical Research Laboratories, Toray Industries, Inc., 6-10-1 \\ Tebiro, Kamakura, Kanagawa 248-8555 and ${ }^{5)}$ Department of Veterinary Pathology, Faculty of Agriculture, Veterinary Medicine, Iwate \\ University, 3-18-8 Ueda, Morioka, Iwate 020-8555, Japan
}

(Received 6 July 2009/Accepted 11 September 2009/Published online in J-STAGE 13 November 2009)

ABSTRACT. We have developed an in vivo medium-term liver initiation assay system to detect initiation activities of chemicals on multiorgan carcinogenesis. However, cell proliferation stimuli during the test chemical treatment period, required in the previously used assay models using adult rats, are laborious; moreover, those cause decrease of hepatic metabolic enzymes and psychological and physical discomfort to animals resulting in inaccurate interpretation. Therefore, we investigated the utility of another in vivo medium-term liver initiation assay model using 4-week-old rats without the cell proliferation stimuli. In this study, we confirmed that 4-week-old and 4.5week-old male rats have high hepatocyte proliferation activity and similar enzyme activities of hepatic Cytochrome P450 subtypes as compared with 8-week-old male rats. Next, the in vivo medium-term liver initiation assay model using 4-week-old rats without cell proliferation stimuli was evaluated for the detection of the initiation activity of 1,2-dimethylhydrazine (DMH), which is a well-known genotoxic carcinogen. Four-week-old rats were orally administered DMH (single dose, 4 or $16 \mathrm{mg} / \mathrm{kg}$; or 4 -day repeat, 1 or $4 \mathrm{mg} / \mathrm{kg}$ ); subsequently, these rats were treated promotion treatment consisted of administration of 2-acetylaminofluorene and carbon tetrachloride. Four weeks after the first DMH administration, the glutathione S-transferase placental form (GST-P)-positive foci induced by DMH in the liver was measured immunohistochemically. The inductions of GST-P-positive foci in all DMH-treated groups were dose-dependent, duration-dependent and significantly higher than that in non-DMH-treated group. From these results, our assay model was detected the initiation activity of DMH simply, and would be useful to evaluate the carcinogenicity of chemicals.

KEY WORDS: 1,2-dimethylhydrazine (DMH)Introduction, carcinogenesis, GST-P-positive cell foci, liver, rat.

J. Vet. Med. Sci. 72(1): 43-53, 2010

Several models are available today for studying the mechanism and activity of carcinogenesis in vivo, most comprising multistage studies involving initiation, promotion, and progression [15]. In vivo medium-term carcinogenic assays based on the multi-stage carcinogenesis hypothesis have been developed in order to bridge the gap between long-term in vivo carcinogenicity studies and shortterm in vitro screening tests $[16,22,47,53]$. The Ito model for the detection of the promotion activity in the liver has already been validated using a long list of chemicals and is widely used to detect the promotion activities of chemicals $[23,24]$. Initiation is also a key event in multi-stage carcinogenesis, resulting from complicated processes in vivo [17]. Therefore, an in vivo medium-term liver initiation assay model has also been developed to detect initiation activity of chemicals, and 26 well-known chemicals have been evaluated [38].

The medium-term liver initiation assay model could detect genotoxic carcinogens, regardless of the target organ, with reference to the induction of glutathione S-transferase

\footnotetext{
* Correspondence to: Dr. SAKai, H., Laboratory of Veterinary Pathology, Faculty of Applied Biological Sciences, Gifu University, 1-1 Yanagido, Gifu 501-1193, Japan. e-mail: shiroki@cc.gifu-u.ac.jp.
}

placental form (GST-P) positive foci in rat livers [38]. GST-P-positive cells were greatly increased in putative neoplastic hepatocellular foci, nodules, and carcinomas [48]. GST-P-positive cells were detectable within days of a single administration of various initiating hepatocarcinogens including diethylnitrosamine (DEN) and aflatoxin B1, but not with promotors and non-carcinogenic agents [30, 31]. Hence, the initiation activity of chemicals can be detected by the measurement of GST-P-positive foci as an end-point marker within a relatively short period because GST-P-positive cells can be considered to be initiated and to be capable of evolving into hepatic preneoplastic lesions [29, 32].

Cell proliferation and metabolism are an essential part of the carcinogenic process. Cell proliferation participates in inducing the mutation of DNA during the initiation of cancer $[5,6]$. Most chemical carcinogens are procarcinogens that need to be converted to true carcinogens by metabolic activation [18]. The metabolic enzymes in the liver, e.g., cytochrome P450 (CYP), are responsible for such bioactivation and play key roles. For this reason, high cell proliferation activity and adequate metabolic enzyme activity in the liver during administration of test chemical are essential to detect initiation activity.

Partial hepatectomy $(\mathrm{PH})$ strongly induces hepatocyte 
proliferation and is widely utilized as a cell proliferation stimulus in the medium-term liver initiation assay model $[19,25,38,46]$. However, performing PH involves certain problems. First, surgical hepatectomy requires technical expertise and is time consuming, especially when large numbers of experimental animals are to be used. Second, $\mathrm{PH}$ causes pain to the animals; moreover, a high mortality is observed after the administration of toxic chemicals because of the high hepatotoxicity induced by the synergistic effect of $\mathrm{PH}$ and the toxic chemical. Third, hepatocyte proliferation after $\mathrm{PH}$ is sharply variable; it is therefore easy to miss the time points of high hepatocyte proliferation and high initiation activity [37].

Chemical hepatectomy $(\mathrm{CH})$ and the fasting/refeeding method are very simple as compared with $\mathrm{PH}$, but these methods also entail certain problems. Hepatotoxicants such as carbon tetrachloride $\left(\mathrm{CCl}_{4}\right)$, allyl alcohol, and d-galactosamine have been used for $\mathrm{CH}$; however, although they induced hepatocyte proliferation, the induction of GST-Ppositive foci in the medium-term liver initiation assay model with these cell proliferation stimuli was lower than that with $\mathrm{PH}$ in previous studies [27, 33, 39-41]. The reason is possibly that the induction of hepatocyte proliferation after the administration of these hepatotoxicants was lower than that after $\mathrm{PH}$; moreover, when hepatocyte proliferation activity was increased, the hepatic metabolic enzymes causing metabolic activation of procarcinogen were markedly decreased by hepatotoxicity of these hepatotoxicants. The fasting/ refeeding method consists of fasting for 4 days and refeeding for 1 day before administering the test chemical. The induction of GST-P-positive foci in the medium-term liver initiation assay model with the fasting/refeeding method was similar to that observed with $\mathrm{PH}$ [9]. However, the fasting/refeeding method has only been tested using diethylnitrosamine (DEN)-a well-known liver carcinogen; moreover, 4-day fasting causes physical and psychological discomfort to the animals, including a decrease in body weight.

The use of proliferating tissue is a prerequisite for the medium-term liver initiation assay model, and another method that can induce high hepatic proliferation activity without proliferation stimuli such as $\mathrm{PH}$ is desirable. Espandiari et al. [9] reported that the medium-term liver initiation assay model using neonatal rats during the initiation phase achieved satisfactory results without cell proliferation stimuli identical to the model with PH in 8-week-old rats. Nevertheless, the model with neonatal rats has only been tested using DEN, and requires a long study period of 14 weeks. Moreover, it is considered that neonatal rats have inadequate metabolic enzyme activities in the liver for the metabolic activation of test chemical.

On the other hand, the livers of 4-week-old rats are still growing, and have high hepatocyte proliferation activity and similar enzyme activities of hepatic CYP as compared with that in adult rats $[12,26,35]$. Hence, our study aimed to investigate the utility of 4-week-old rats in the medium-term liver initiation assay model without a cell proliferation stimulus, and current study was consisted of 2 experiments. In experiment I, the hepatocyte kinetics and the enzyme activities of several hepatic CYP isozymes in 4-week-old, 4.5week-old, and 8-week-old Fischer-344 male rats were evaluated to confirm superiority and continuousness of hepatocyte proliferation activity and similarity of hepatic metabolization activity at 4 weeks of age as compared with those at 8 weeks of age. In experiment II, the in vivo medium-term liver initiation assay model using 4-week-old rats without a proliferation stimulus was evaluated for the detection of the initiation activity of 1,2-dimethylhydrazine $(\mathrm{DMH})$, which is a well-known genotoxic carcinogen targeting the colon and a non-hepatocarcinogen in rodents [52, 55]; the utility of this model using 4-week-old rats was evaluated.

\section{MATERIALS AND METHODS}

Chemicals: DMH dihydrochloride and 2-acetylaminofluorene (2-AAF) were purchased from Tokyo Chemical Industry Ltd. (Tokyo, Japan). The animals' feed (CA-1) containing $0.015 \%$ of $2-\mathrm{AAF}$ and $10 \%$ corn oil was obtained from Clea Japan Inc. (Tokyo, Japan). $\mathrm{CCl}_{4}$ was purchased from Wako Pure Chemical Industries Ltd. (Tokyo, Japan). 5-Bromo-2'-deoxyuridine (BrdU), chlorzoxazone (CZX), 6-hydroxychlorzoxazone (6-OH CZX), resorufin, ethoxyresorufin, $6 \beta$-hydroxytestosterone ( $6 \beta$-OH TS), and $\beta$-nicotinamide adenine dinucleotide 2 '-phosphate reduced tetrasodium salt (NADPH) were purchased from SigmaAldrich Inc. (St. Louis, MO, U.S.A.). $7 \alpha$-hydroxytestosterone ( $7 \alpha-\mathrm{OH}$ TS) and $16 \beta$-hydroxytestosterone $(16 \beta$-OH TS) were obtained from UFC Ltd. (Manchester, Grate Manchester, UK). Testosterone was purchased from Biogenesis Ltd. (Poole, Dorset, UK). The Bio-Rad Protein Assay kit used for the determination of microsomal protein content was obtained from Bio-Rad Laboratories (Hercules, CA, U.S.A.).

Animals: Male Fischer-344 rats were obtained from Charles River Japan (Atsugi, Japan), and 3-4 animals were housed per plastic cage on softwood chip bedding. These animals were maintained under constant conditions (12 hr light/dark cycle, $60 \%$ humidity at $22^{\circ} \mathrm{C} \pm 2{ }^{\circ} \mathrm{C}$ ), and fed on an CA-1 diet (Clea Japan Inc.) and tap water ad libitum.

Experimental protocols: In experiment I, hepatocyte proliferation kinetics were evaluated in 4-week-old, 4-5-weekold, and 8-week-old rats. The rats were intraperitoneally administered BrdU (100 mg/kg) dissolved in saline, $1 \mathrm{hr}$ before autopsy. After euthanasia by exsanguination under diethyl ether anesthesia, the liver slices were fixed in $10 \%$ neutral buffered formalin for approximately $24 \mathrm{hr}$ and processed for embedding in paraffin for hematoxylin and eosin (H.E.) staining as well as immunohistochemical examination of BrdU-labeled cells. Pieces of fresh liver tissue were rinsed in ice-cold saline and immediately frozen in liquid nitrogen and stored at approximately $-80^{\circ} \mathrm{C}$ until use for the measurement of enzyme activities of several hepatic CYP isozymes.

In experiment II (Fig. 1), the in vivo medium-term liver 


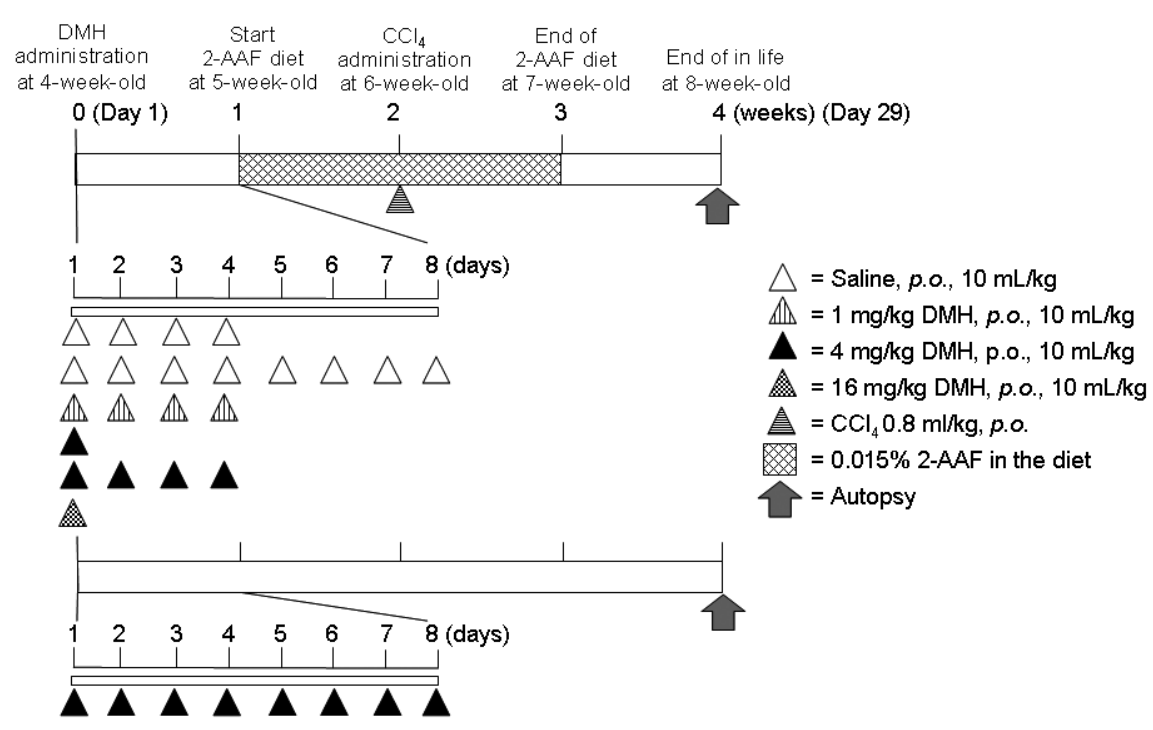

Fig. 1. Schematic representation of the protocol in experiment II: See Materials and Methods for further details.

initiation assay model using 4-week-old rats was evaluated to detect the initiation activity of DMH. In accordance with the dose and administration period of DMH, 4-week-old rats after 1-week acclimatization were divided into 5 groups as follows: $1 \mathrm{mg} / \mathrm{kg}$ /day single administration, $1 \mathrm{mg} / \mathrm{kg} /$ day $4-$ day administration, $4 \mathrm{mg} / \mathrm{kg} /$ day single administration, 4 $\mathrm{mg} / \mathrm{kg} /$ day 4-day administration, and $16 \mathrm{mg} / \mathrm{kg} /$ day single administration. DMH was dissolved in saline and administered orally once daily. The weights of the 4-week-old rats ranged from 52.1 to $73.3 \mathrm{~g}$ at the first administration of $\mathrm{DMH}$. The control group received no DMH. All rats were fed basal diet (CA-1) for 1 week after the first DMH administration, and then the diet containing $0.015 \% 2$-AAF for the following 2 weeks. At 2 weeks after the first DMH administration, all animals were orally administered a single dose of $\mathrm{CCl}_{4}(0.8 \mathrm{ml} / \mathrm{kg})$ dissolved in corn oil. Additionally, the non-promotion group was only administered $4 \mathrm{mg} / \mathrm{kg}$ /day $\mathrm{DMH}$ for 8 days without providing the diet containing 2$\mathrm{AAF}$ and orally administration of $\mathrm{CCl}_{4}$. At the end of week 4 after the first DMH administration, the survivors were euthanized, and their liver slices were fixed in $10 \%$ neutral buffered formalin for immunohistochemical examination of GST-P-positive foci.

All procedures described in this study were approved by the Gifu University Committee on Animal Care and Supply.

Preparation of hepatic microsomes: Hepatic microsomes were prepared as described previously [36, 54]. Approximately $1-2 \mathrm{~g}$ of liver tissue was homogenized (Polytron Homogenizer; GTR-1000, Tokyo Rikakiki Co., Ltd., Tokyo, Japan) in a 3-volume homogenization buffer (0.1-M Tris acetate, 0.1-M KCl, 1-mM EDTA, $5 \mu \mathrm{g} / \mathrm{m} l$ butylated hydroxytoluene, and $40 \mu \mathrm{g} / \mathrm{m} l$ phenylmethylsulfonyl fluoride). The homogenate was centrifuged at $700 \times \mathrm{g}$ for 10 $\min$ at $4^{\circ} \mathrm{C}$, and the supernatant was centrifuged at $12,000 \times$ $\mathrm{g}$ for $20 \mathrm{~min}$ at $4^{\circ} \mathrm{C}$. The supernatant was ultracentrifuged at $105,000 \times \mathrm{g}$ for $60 \mathrm{~min}$ at $4^{\circ} \mathrm{C}$; subsequently, the pellet was suspended in sucrose phosphate buffer (0.1-M phosphate buffer, 0.25-M sucrose, and 0.1-mM EDTA). These aliquots were stored at $-80^{\circ} \mathrm{C}$ until further use.

Microsomal protein concentrations were determined by the Bradford's protein assay method using the Bio-Rad Protein Assay kit (Coomassie Brilliant Blue G-250) and bovine serum albumin as the standard, according to the manufacturer's protocol.

Total cytochrome P450 measurement: The content of total CYP was measured photometrically using the method described by Omura and Sato [34]. The microsomal sample was further diluted to approximately $1 \mu \mathrm{g} / \mathrm{m} l$ microsomal protein with phosphate-glycerol buffer $(20: 1 \mathrm{v} / \mathrm{v}, 0.1 \mathrm{M}$ phosphate buffer: glycerol). Total cytochrome $\mathrm{P} 450$ was determined by the formation of the carbon monoxide difference spectrum between $450 \mathrm{~nm}$ and $490 \mathrm{~nm}$ absorbance following dithionite reduction.

\section{Enzyme activity determination}

Ethoxyresorufin O-deethylase activity: Ethoxyresorufin O-deethylase activity was quantified by the fluorometric measurement of resorufin, which is 7-ethoxyresorufin metabolite [4]. The reaction mixture comprising 15- $\mu \mathrm{M} 7-$ ethoxyresorufin, 1-mM NADPH, 3-mM magnesium chloride, and phosphate buffer $(0.1 \mathrm{M}, \mathrm{pH} 7.4)$ was prepared to a total volume of $180 \mathrm{ml}$ and placed in one well of a microplate. All incubation mixtures were preincubated for $10 \mathrm{~min}$ at $37^{\circ} \mathrm{C}$. The reactions were initiated by the addition of 20 $\mu l$ of $1 \mu \mathrm{g} / \mathrm{m} l$ microsomal protein and fluorometrically monitored (excitation, $544 \mathrm{~nm}$; emission, $590 \mathrm{~nm}$ ) at $37^{\circ} \mathrm{C}$ for 3 min in the microplate reader.

Testosterone hydroxylase activities: CYP subtypes stereospecifically hydroxylate testosterone at certain ring posi- 
tions to produce several metabolites [3, 42]. CYP2A, CYP2B, and CYP3A activities were measured by monitoring the $7 \alpha-, 16 \beta$-, and $6 \beta$-hydroxylation of testosterone using high-performance liquid chromatography (HPLC) [56]. The reaction mixture comprising $5 \mu l$ of 20 -mM testosterone, $50 \mu l$ of $10-\mathrm{mM}$ NADPH, and phosphate buffer $(0.1 \mathrm{M}, \mathrm{pH} 7.4)$ was prepared to a total volume of $450 \mu \mathrm{l}$. All incubation mixtures were preincubated for $5 \mathrm{~min}$ at $37^{\circ} \mathrm{C}$ in a shaking water bath. The reactions were initiated by the addition of $50 \mu \mathrm{l}$ of $5 \mathrm{mg} / \mu \mathrm{l}$ microsomal protein and terminated by the addition of $250 \mu \mathrm{l}$ ice-cold methanol after incubation for $10 \mathrm{~min}$ at $37^{\circ} \mathrm{C}$. Microsomal protein was removed from suspension by centrifugation $(14,000 \times \mathrm{g}, 10$ $\mathrm{min})$, and $50 \mu l$ of the supernatant was injected directly into the HPLC system. A Hypersil BDS $\mathrm{C}_{18}, 5 \mu \mathrm{m}(10 \mathrm{~cm} \times 0.46$ $\mathrm{cm}$ ) analytical column (Phenomenex, Macclesfield, UK) maintained at a temperature of $40^{\circ} \mathrm{C}$ was used for HPLC. The HPLC analysis used a gradient in which solvent $\mathrm{A}$ (water) was varied from $80 \%(0-10 \mathrm{~min})$ to $72 \%(10-13$ $\mathrm{min}$ ) to $80 \%$ (13-16 $\mathrm{min})$, solvent B (acetonitrile) form $10 \%$ $(0-10 \mathrm{~min})$ to $14 \%(10-13 \mathrm{~min})$ to $10 \%(13-16 \mathrm{~min})$, and solvent $\mathrm{C}$ (tetrahydrofuran) from $10 \%(0-10 \mathrm{~min})$ to $14 \%$ (10-13 $\mathrm{min})$ to $14 \%(13-16 \mathrm{~min})$ of total flow volume. The flow rate was constant at $1.0 \mu \mathrm{l} / \mathrm{min}$. Testosterone metabolite formations ( $7 \alpha-\mathrm{OH} \mathrm{TS}, 16 \beta-\mathrm{OH} \mathrm{TS}$, and $6 \beta-\mathrm{OH}$ TS) were measured by in-line UV detection at $255 \mathrm{~nm}$, and the chromatograms were analyzed.

Chlorzoxazone hydroxylase activity: CYP2E1 activity was monitored by HPLC assay of the 6-hydroxylation of CZX as described by Leclercq et al. [28]. The reaction mixture comprising $20 \mu \mathrm{g}$ of CZX, $0.6 \mathrm{mg}$ of NADPH, $50 \mu \mathrm{l}$ of 0.1-M magnesium chloride, and 0.1-M Tris buffer ( $\mathrm{pH} 7.6$ ) was prepared to a total volume of $450 \mu l$. The reaction was initiated by the addition of $50 \mu \mathrm{lof} 3 \mathrm{mg} / \mu \mathrm{lmicrosomal}$ protein and terminated by the addition of $200 \mu \mathrm{l}$ ice-cold zinc sulfate $(15 \%, \mathrm{w} / \mathrm{v})$ after incubation for $20 \mathrm{~min}$ at $37^{\circ} \mathrm{C}$. Microsomal protein was removed from suspension by centrifugation $(14,000 \times \mathrm{g}, 10 \mathrm{~min})$, and $50 \mu \mathrm{l}$ of the supernatant injected directly into the HPLC system. An Aquasil $\mathrm{C}_{18}, 3 \mathrm{~mm}(15 \mathrm{~cm} \times 0.46 \mathrm{~cm})$ analytical column (Thermo Fisher Science Inc., Waltham, MA, U.S.A.) maintained at a temperature of $25^{\circ} \mathrm{C}$ was used. The mobile phase composition was $10-\mathrm{mM}$ ammonium acetate buffer-acetonitrile $(75: 25, \mathrm{v} / \mathrm{v})$ at a flow rate of $1.0 \mu \mathrm{l} / \mathrm{min}$. Formation of $6-\mathrm{OH}$ CZX was measured by in-line UV detection at $287 \mathrm{~nm}$, following which the chromatograms were analyzed.

Immunohistochemistry: The avidin-biotin complex method has been used to demonstrate BrdU-labeled hepatocytes, in the S-phase of the cell cycle, and GST-P-positive foci $[2,20]$. The sections were incubated with peroxidaseblocking solution (DAKO Cytomation Inc., Carpinteria, CA, U.S.A.) for 5 min to block any endogenous peroxidase activity, and incubated with Protein block serum-Free (DAKO Cytomation Inc.) for 10 min for nonspecific binding. For BrdU-immunostaining, the section was treated with $2-\mathrm{N} \mathrm{HCl}$ for $30 \mathrm{~min}$ and then $0.05 \%$ pepsin solution containing $0.01-\mathrm{N} \mathrm{HCl}$ for $12 \mathrm{~min}$ to reactivate the target antigen after blocking the endogenous peroxidase activity. All subsequent operations were performed after washing the sections with TBS containing $0.1 \%$ Tween 20 . The sections were incubated with mouse monoclonal antibody against BrdU (DAKO Cytomation Inc.) diluted at 1:50 or rabbit polyclonal antibody against rat GST-P (MBL, Nagoya, Japan) for $60 \mathrm{~min}$ at room temperature. Subsequently, the sections for anti-BrdU and anti-GST-P immunostain were incubated with anti-mouse goat immunoglobulins (DAKO Cytomation Inc.) diluted at 1:400 for 30 min or biotinylated anti-rabbit immunoglobulins in LSAB2 kit (DAKO Cytomation Inc.) for $10 \mathrm{~min}$ at room temperature. Next, streptavidin conjugated to horseradish peroxidase was reacted with the sections for the production of the avidin-biotin complex using the VECTASTAIN Elite ABC kit (Vector Laboratories, Burlingame, CA, U.S.A.) for $30 \mathrm{~min}$ or the LSAB2 kit (DAKO Cytomation Inc.) for $10 \mathrm{~min}$. The reaction was detected using 3,3'-diaminobenzidine (DAB) as a chromogen in the DAB kit (DAKO Cytomation Inc.).

At least 6 areas per liver lobe were examined at $100 \times$ magnification, and the percentage of BrdU-labeled hepatocytes from a total of 2000 or more hepatocytes was calculated. On the other hand, the numbers and areas of GST-Ppositive foci $>0.1 \mathrm{~mm}$ in diameter and the total areas of liver sections were quantified using eCongnition (Definiens, Munich, Germany), which is an innovative object-based quantitative image analysis system.

Statistical analysis: Descriptive statistics (mean \pm SD) were used to report the liver weight, relative liver weight, BrdU-labeled hepatocyte index, hepatic total CYP content, enzyme activities of hepatic CYP subtypes and numbers and areas of GST-P foci. The statistical significance of differences in quantitative data in experiments I and II was analyzed using $t$-tests and pairwise multiple comparisons using the SAS non-clinical package (SAS Institute Japan, Japan). The level of significance was set at less than $5 \%$.

In the $t$-tests, the homogeneity of the variance was tested using the F-test at a significance level of 5\%. Student's $t$ test was applied when homogeneous variance was demonstrated, and Welch's $t$-test was applied when the variance was not homogeneous. In multiple comparisons, the homogeneity of the variance was tested using the Bartlett method at a significance level of 5\%. When homogeneous variance was demonstrated, a one-way ANOVA analysis was applied. The mean values were further compared using Dunnett's multiple comparison only when the one-way ANOVA analysis of variance detected significant differences between the control group and the evaluated groups. When the Bartlett test showed that the variance was not homogeneous, the Kruskal-Wallis test was applied. Steel's test of means was performed only when the Kruskal-Wallis test detected significant differences between the control group and the evaluated groups.

\section{RESULTS}

Hepatocyte proliferation and hepatic CYP in 4-week-old, 
4.5-week-old, and 8-week-old rats: The mean values for liver weight and relative liver weight for the experimental animals are indicated in Fig. 2. The mean liver weights in 4week-old and 4.5-week-old rats were significantly lower than that in 8 -week-old rats, but the mean relative liver weights in 4-week-old and 4.5-week-old rats were significantly higher than that in 8-week-old rats. Histological examination (Fig. 3) showed that the lobular pattern was similar between 4-week-old rats and 8-week-old rats; however, the hepatocytes in the middle zone of the liver lobule in 4-week-old rats seemed to be smaller than those in the 8week-old rats. Several mitotic figures in hepatocytes were observed similarly in the middle and periportal zones in both 4-week-old rats and 8-week-old rats. However, the BrdU-labeled hepatocytes in 4-week-old rats were observed more frequently in the pan-lobule, but those in 8-week-old rats were few in the middle and periportal zones. The BrdUlabeled hepatocyte index is indicated in Fig. 4. The BrdUlabeled hepatocyte index values in 4-week-old and 4.5week-old rats were approximately 3 and 2 times higher than that in 8-week-old rats, respectively.

The hepatic CYP contents and enzyme activities of CYP1A, CYP2A, CYP2B, CYP2E, and CYP3A in each age group are indicated in Fig. 5. The CYP contents in 4-weekold and 4.5-week-old rats were similar to those in 8-weekold rats. The enzyme activities of CYP1A, CYP2B, CYP2E, and CYP3A in the livers of 4-week-old and 4.5week-old rats were almost equivalent to those in 8 -week-old rats. The enzyme activity of hepatic CYP2A in 4-week-old and 4.5-week-old rats was approximately 2 times higher than that in 8-week-old rats.

GST-P-positive Foci induced by DMH administration in the medium-term liver initiation assay model using 4-weekold rats: Data for the numbers and areas of GST-P-positive foci per unit area of liver sections in experiment II are summarized in Fig. 6.

The numbers and areas of GST-P-positive foci in the rats administered DMH were significantly increased as compared with those in the control rats, and they showed a dosedependency. The values for GST-P-positive foci were similar between the rats treated with DMH $1 \mathrm{mg} / \mathrm{kg} /$ day for 4 days and the rats treated with DMH $4 \mathrm{mg} / \mathrm{kg} /$ day for 1 day. In the same way, GST-P-positive foci in the rats treated with DMH $4 \mathrm{mg} / \mathrm{kg} /$ day for 4 days were similarly induced as compared with those in the group treated with DMH $16 \mathrm{mg} /$ $\mathrm{kg}$ /day for 1 day. Histopathologically, large GST-P foci occupying several lobules and causing distinct compression of adjacent parenchyma were observed in 3 rats treated with DMH $4 \mathrm{mg} / \mathrm{kg} /$ day for 4 days and 1 rat treated with DMH 16 $\mathrm{mg} / \mathrm{kg} /$ day for 1 day (Fig. 7). Numbers of the large GST-P foci in the liver of these rats was mainly 1-2, but 7 large GST-P foci were observed in the liver of 1 rat treated with DMH $4 \mathrm{mg} / \mathrm{kg} /$ day for 4 days. On the other hand, the numbers and areas of GST-P-positive foci in the rats administered $4 \mathrm{mg} / \mathrm{kg} /$ day $\mathrm{DMH}$ for 8 days without the promotion treatment consisting of $\mathrm{CCl}_{4}$ and 2-AAF administration were not increased as compared with that in the control rats.

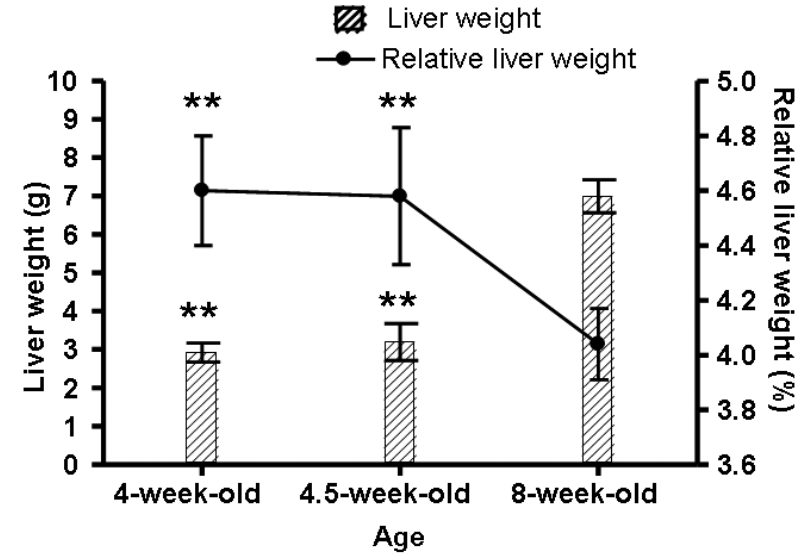

Fig. 2. Liver weight and relative liver weight as compared with body weights in the 4-week-old, 4.5-week-old, and 8-week-old rats. Data are represented as mean \pm SD values for $4-5$ animals in each group. $* * P<0.01$, significantly different as compared with values for 8 -week-old rats.

\section{DISCUSSION}

Several in vivo carcinogenic study methods, including the Solt-Farbar protocol, have been developed to study multistage carcinogenesis in the liver [10]. Initiation is an important step in multistage carcinogenesis, and the initiation activity of test chemicals can be detected in a medium-term liver initiation assay model by cell proliferation stimuli including $\mathrm{PH}$ just before the treatment of test chemical, in combination with promotion treatment consisted of administration of a necrogenic dose of $\mathrm{CCl}_{4}$ and a low dose of 2AAF after test chemical treatment. High hepatocyte proliferation activity and sufficient metabolic activation by metabolic enzymes for administration of the test chemical are important in detecting the initiation activity of the test chemical. This study investigated the utility of using 4week-old rats to replace an in vivo liver initiation assay model using a cell proliferation stimulus.

As shown in the results of BrdU-labeled cell kinetics (Fig. 4), the hepatocyte proliferation index in the liver of 4week-old rats is approximately 3 times higher than that in 8week-old rats, and the GST-P-positive foci in the rats administered a single DMH dose at 4 weeks of age were induced significantly as compared with those in the control rats in experiment II (Fig. 6). From these results, 4-weekold rats is considered to be advantageous in the mediumterm liver initiation assay model because it does not require cell proliferation stimuli causing psychological/physical pain and unexpected effect before administration of test chemical. In the previous articles, Furukawa et al. [12] reported that BrdU labeling index of hepatocyte in the male Wistar-rats at $4,5,6,7$ and 8 weeks of age were approximately $2.5 \%, 1.5 \%, 1.2 \%, 1.0 \%$ and $0.3 \%$, respectively. In the liver micronucleous assay, in which high hepatocyte proliferation activity facilitates the detection of mutagenicity, Suzuki et al. [45] reported that the incidence of the num- 

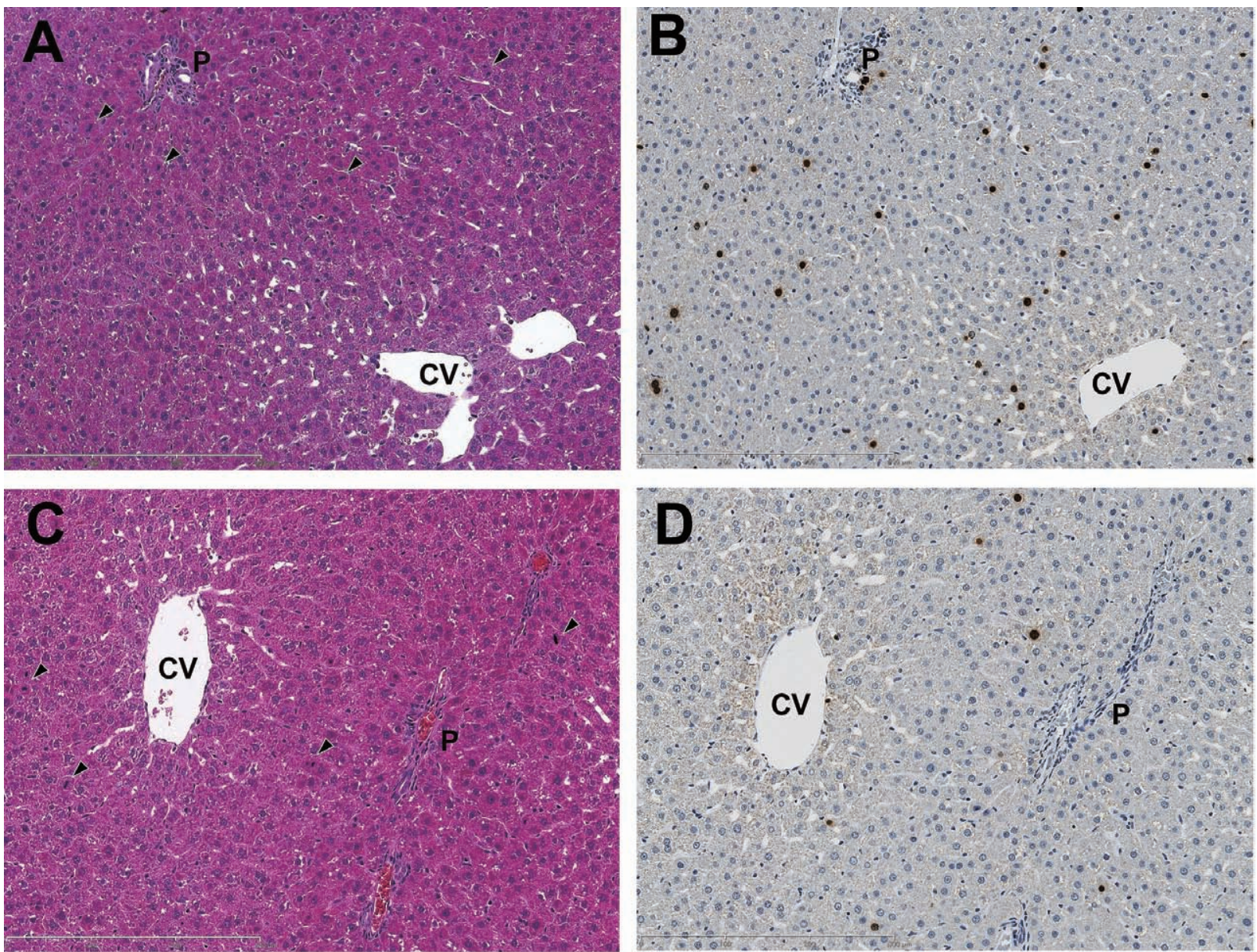

Fig. 3. Histological differences in livers of 4-week-old and 8-week-old rats. HE staining (A: 4-week-old, C: 8-week-old) and BrdU immunostaining (B: 4-week-old, D: 8-week-old) in experiment I. The lobular pattern was similar in 4-week-old rats (A) and 8-week-old rats (C), but the hepatocytes in the middle zone of the liver lobule of 4-week-old rats seemed to be smaller than the hepatocytes of 8-week-old rats. Although several mitotic figures (arrowhead) were observed similarly in the middle and periportal zones in both 4-week-old rats and 8-week-old rats, the BrdU-labeled hepatocytes in 4-week-old rats (B) were observed more frequently in the pan-lobule as compared with those in 8-week-old rats, which are few in the middle and periportal zones (D). CV: central vein, P: portal triad. Bar is 300 micrometers.

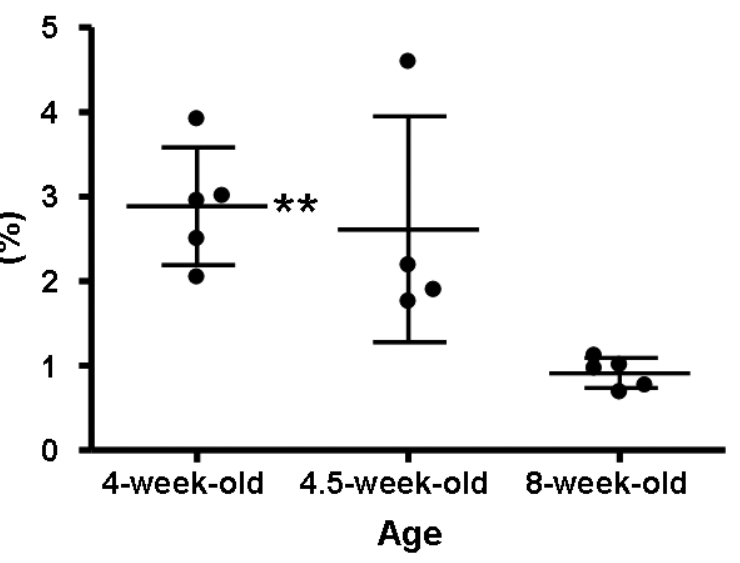

Fig. 4. Data plot of BrdU-labeled hepatocyte indices in the 4week-old, 4.5-week-old, and 8-week-old rats. Middle line indicates mean values, and the upper and lower lines represent standard deviation. $* * P<0.01$, significantly different as compared with 8 -week-old rats. ber of micronucleated hepatocytes (MNHEP) induced by DEN administration in the livers of 4-week-old rats was significantly higher than that in 7-week-old and 9-week-old rats; moreover, the models using 4-week-old rats without cell proliferation stimulus during administration of test chemical indicated equal or even higher practicability than did 6-week-old rats undergoing $\mathrm{PH}$ before test chemical dosing. Hence, using 4-week-old rats is able to replaces using cell proliferation stimuli as induction of hepatocyte proliferation activity before administration of test chemical because the hepatocyte proliferation activity in 4-week-old rats is significantly higher than adult rats, and it is suggested that using 4-week-old rats is reasonable for detecting initiation activity.

Other advantages in using 4-week-old rats concern the animal experiment period and the requisite amounts of test chemical. The previous assay models required detecting initiation activity of carcinogens for more than 5 weeks, but 

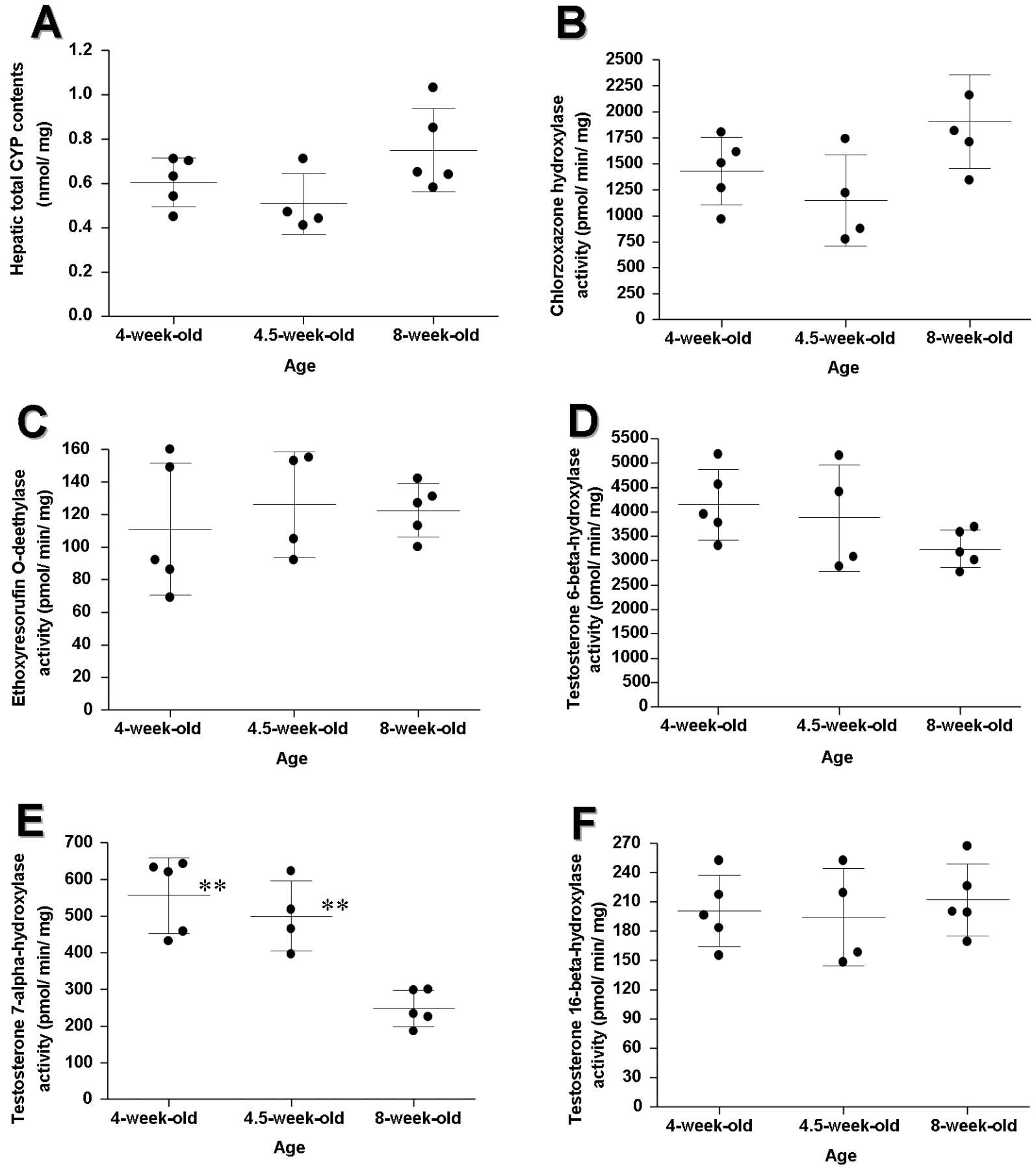

Fig. 5. Hepatic total CYP content (A) and enzyme activities of hepatic CYP 2E (B), CYP 1A (C), CYP3A (D), CYP2A (E) and CYP2B (F) in 4-week-old, 4.5-week-old, and 8-week-old rats. Middle lines represent mean values, and upper and lower lines indicate standard deviation. ** $P<0.01$, significantly different as compared with 8 -week-old rats.

the current study assay model required detecting initiation activity of DMH for only 4 weeks. The body weight in 4week-old rats ranges from $25 \%$ to $33 \%$ of that of 7 - or 8 week-old rats; accordingly, the requisite amount of test chemical for detecting initiation activity in this model using 4-week-old rats is less than that in previous models using older animals.

Multiple low-dose administrations proved superior to the single high-dose administration when the margin of test chemical between toxic/lethal dose level and genotoxic/car- 


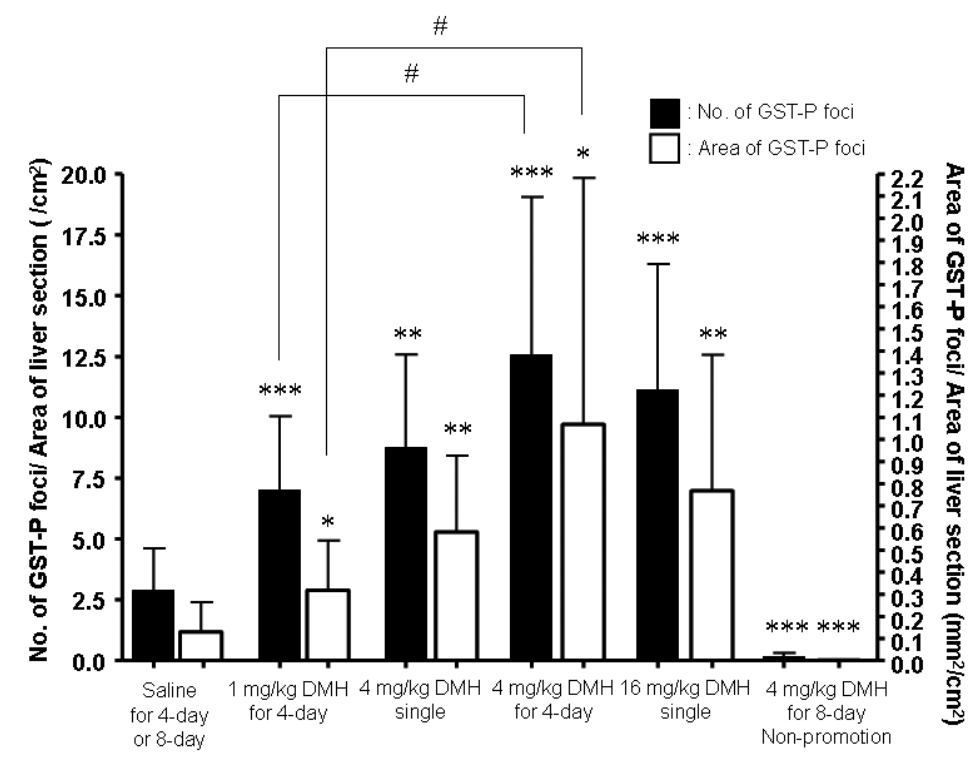

Fig. 6. Numbers and areas of GST-P-positive foci $>0.1 \mathrm{~mm}$ in diameter in the group administered DMH or saline in experiment II. Data represent mean \pm SD values for 8-17 animals in each group, except $4 \mathrm{mg} / \mathrm{kg}$ DMH administration for 8 days without promotion treatment consisting of $\mathrm{CCl}_{4}$ and 2-AAF administration ( 3 animals). $* P<0.05, * * P<0.01$, and $* * * P<0.001$, statistically significant difference as compared with animals that were administered saline. ${ }^{\#} P<0.05$, significant difference between the 4-day DMH $1-\mathrm{mg} / \mathrm{kg} / \mathrm{day}$ and $4-\mathrm{mg} / \mathrm{kg} / \mathrm{day}$ administration groups.
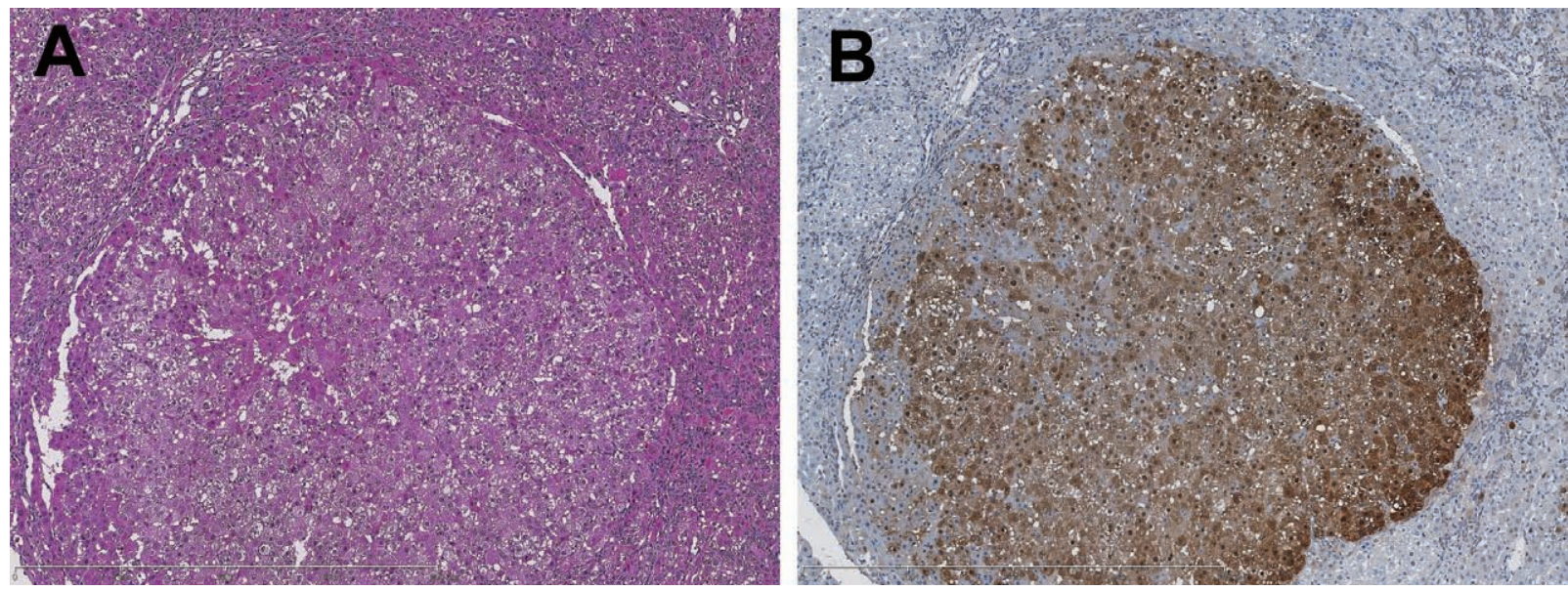

Fig. 7. GST-P-positive foci induced by DMH administration in the medium-term liver initiation assay model using 4-week-old rats. Large GST-P foci occupying several lobules and causing distinct compression of adjacent parenchyma were observed in the liver treated with DMH $4 \mathrm{mg} / \mathrm{kg} /$ day for 4 days. A: HE staining, B: GST-P immunostaining. Bar is 800 micrometers.

cinogenic dose level was small. Human exposure to environmental carcinogens is usually limited to low concentrations and human are generally exposed to such carcinogens over a long-term period $[1,7,49]$; therefore, multiple low-dose administration would be expected to be superior to single high-dose administration for extrapolation to carcinogenesis in humans. Generally, previous assay models using a cell proliferation stimulus tested only single or multiple doses over 1-day administration of test chemi- cals because the induction of hepatocyte proliferation could be maintained only for approximately 1 day $[2,39]$. In the current study, hepatocyte proliferation activity in 4-weekold rats was significantly higher than that in 8 -week-old rats and continued at high levels until 4.5 weeks of age in experiment I, and the induction of GST-P-positive foci by 4-day divided doses of DMH was approximately equal to that with the same total single dose of DMH in experiment II. From these results, using 4-week-old rats in the medium-term 
liver initiation assay models not only makes it unnecessary to use a cell proliferation stimulus but also enables to detect the initiation activity of test chemicals with repeat administration of ones, which could not be detected the initiation activity in previous assay models.

Most carcinogens require metabolic activation, and this is mainly catalyzed by CYP. CYP2E1 metabolizes nitrosamines such as DEN [51] and hydrazine derivatives such as $\mathrm{DMH}[11,44]$. In previous studies, it has been reported that the enzyme activities of hepatic CYP2A in 3- or 4-week-old $\mathrm{SD}$ rats were higher than that in 7- or 8-week-old SD rats, and enzyme activities of hepatic CYP1A, CYP2B, CYP2E, and CYP3A in 3- or 4-week-old rats were similar as compared with that in 7 - or 8 -week-old rats $[8,43]$. Kato and Yamazoe [26] reported that expression of hepatic CYP1A2, CYP2A1, CYP2B1, CYP2B2, CYP2E1, CYP3A1, and CYP3A2 approximately reached maximum levels in 3week-old rats. On the other hand, expressions of hepatic metabolic enzymes such as CYP1A1, CYP1A2, CYP2A1, CYP2A2, CYP2B1, CYP2B2, and CYP3A2 in neonatal rats aged below 1 week of age were significantly low except for CYP2E1 [8, 21]. Although the utility of the medium-term liver initiation assay model using neonatal rats has been reported [9], it is considered that the metabolic activation of procarcinogens is not adequate in the liver of neonatal rats. In this study, hepatic CYP contents and the enzyme activities of CYP1A, CYP2B, CYP2E, and CYP3A in 4-week-old and 4.5-week-old rats were similar to that in 8-week-old rats, and hepatic CYP2A in 4-week-old and 4.5-week-old rats was approximately 2 times higher than that in 8 -weekold rats (Fig. 5). Therefore, the medium-term liver initiation assay model using 4-week-old rats is able to detect the initiation activity of a procarcinogen such as DMH adequately.

GST-P-positive foci can be strongly stimulated by the application of 2-AAF feeding with cell proliferation treatment. In the previous medium-term liver initiation assay models, the initiated cells could be selectively stimulated to produce altered foci by using an appropriate selection pressure consisting of exposure to 2-AAF in combination with a hepatocyte proliferation stimulus by $\mathrm{CCl}_{4}$ administration $[40,50]$. In experiment II, the induction of GST-P foci in the rats treated with only DMH $4 \mathrm{mg} / \mathrm{kg} /$ day administration for 8 days without the promotion treatment consisting of diet dosing of 2-AAF and oral administration of $\mathrm{CCl}_{4}$ was much lower than that in the control group administered saline with the promotion treatment. From these results, the promotion treatment consisting of 2-AAF and $\mathrm{CCl}_{4}$ administration after formation of initiated cells by test chemical was also necessary for enabling the detection of the initiation activity of test chemicals in medium-term liver initiation assay models using 4-week-old rats. It is likely that juvenile livers may be sensitive to the initiation activity of carcinogens, and carcinogenic risks in children may be higher than those in adults when they are exposed to liver genotoxic carcinogens or liver promotion stimuli such as non-genotoxic carcinogens with mutagens that include various environmental materials. It is considered that further studies are needed to analyze the carcinogenic risk of environmental materials, such as agricultural chemicals, in children.

In conclusion, the use of 4-week-old rats in medium-term liver initiation assay models enables the utilization of the high and sustained hepatocyte proliferation activity with sufficient levels of hepatic metabolic enzymes such as CYP2E1, activating DMH to the ultimate carcinogenic forms. This in vivo assay model without a cell proliferation stimulus during test chemical treatment was capable of evaluating DMH carcinogenicity rapidly and simply with single- or repeat-administration of one, as compared with previous assay models that used cell proliferation stimuli. We suggest that this assay model is better for 3R concept of animal welfare than previous assay models, and expect that the detection sensitivity for initiation activity would improve markedly with this model; especially, with repeat administration of test chemical.

\section{REFERENCES}

1. Ames, B. and Gold, L. 1998. The causes and prevention of cancer: the role of environment. Biotherapy 11: 205-220.

2. Asaoka, Y., Sakai, H., Takahashi, N., Hirata, A., Tsukamoto, T., Yamamoto, M., Yanai, T., Masegi, T. and Tatematsu, M. 2005. Intraperitoneal injection of D-galactosamine provides a potent cell proliferation stimulus for the detection of initiation activities of chemicals in rat liver. J. Appl. Toxicol. 25: 554561.

3. Bandiera, S., Ryan, D., Levin, W. and Thomas, P. 1986. Ageand sex-related expression of cytochromes p450f and P450g in rat liver. Arch. Biochem. Biophys. 248: 658-676.

4. Burke, M., Thompson, S., Weaver, R., Wolf, C. and Mayer, R. 1994. Cytochrome P450 specificities of alkoxyresorufin Odealkylation in human and rat liver. Biochem. Pharmacol. 48: 923-936.

5. Cayama, E., Tsuda, H., Sarma, D. and Farber, E. 1978. Initiation of chemical carcinogenesis requires cell proliferation. Nature 275: 60-62.

6. Cohen, S. and Ellwein, L. 1990. Cell proliferation in carcinogenesis. Science 249: 1007-1011.

7. Constan, A., Yang, R., Baker, D. and Benjamin, S. 1995. A unique pattern of hepatocyte proliferation in F344 rats following long-term exposures to low levels of a chemical mixture of groundwater contaminants. Carcinogenesis 16: 303-310.

8. Elbarbry, F., McNamara, P. and Alcorn, J. 2007. Ontogeny of hepatic CYP1A2 and CYP2E1 expression in rat. J. Biochem. Mol. Toxicol. 21: 41-50.

9. Espandiari, P., Robertson, L.W., Srinivasan, C. and Glauert, H.P. 2005. Comparison of different initiation protocols in the resistant hepatocyte model. Toxicology 206: 373-381.

10. Farber, E., Hartman, S.P., Solt, D. and Cameron, R. 1976. Precancerous Liver Cell Populations and Their Identification. University Park Press, Baltimore.

11. Fiala, E. 1977. Investigations into the metabolism and mode of action of the colon carcinogens 1,2-dimethylhydrazine and azoxymethane. Cancer 40: 2436-2445.

12. Furukawa, S., Tamura, T., Ogawa, I., Goryo, M. and Okada, K. 2003. Effect of juvenile aging hepatocellular proliferation in male Han Wistar (GALAS) rats. J. Toxicol. Pathol. 16: 81-84.

13. Gad, S.C. 2001. Human pharmaceutical products. pp. 9-69. In: 
Regulatory Toxicology (Gad, S.C. ed.). Taylor \& Francis, London.

14. Gerhardsson, de Verdier M., Hagman, U., Peters, R., Steineck, G. and Overvik, E. 1991. Meat, cooking methods and colorectal cancer: a case-referent study in Stockholm. Int. J. Cancer 49: $520-525$.

15. Goldsworthy, T., Hanigan, M. and Pitot, H. 1986. Models of hepatocarcinogenesis in the rat--contrasts and comparisons. Crit. Rev. Toxicol. 17: 61-89.

16. Goldsworthy, T. and Pitot, H. 1985. An approach to the development of a short-term whole-animal bioassay to distinguish initiating agents (incomplete carcinogens), promoting agents, complete carcinogens, and noncarcinogens in rat liver. J. Toxicol. Environ. Health 16: 389-402.

17. Grasl-Kraupp, B., Luebeck, G., Wagne, A., Löw-Baselli, A., de Gunst, M., Waldhör, T., Moolgavkar, S. and Schulte-Hermann, R. 2000. Quantitative analysis of tumor initiation in rat liver: Role of cell replication and cell death (apoptosis). Carcinogenesis 21: 1411-1421.

18. Guengerich, F. 2000. Metabolism of chemical carcinogens. Carcinogenesis 21:345-351.

19. Hirata, A., Tsukamoto, T., Sakai, H., Takasu, S., Ban, H., Imai, T., Totsuka, Y., Nishigaki, R., Wakabayashi, K., Yanai, T, Masegi, T. and Tatematsu, M. 2008. Carcinogenic risk of heterocyclic amines in combination - Assessment with a liver initiation model. Food Chem. Toxicol. 46: 2003-2009.

20. Hsu, S., Raine, L. and Fanger, H. 1981. Use of avidin-biotinperoxidase complex $(\mathrm{ABC})$ in immunoperoxidase techniques: a comparison between $\mathrm{ABC}$ and unlabeled antibody (PAP) procedures. J. Histochem. Cytochem. 29: 577-580.

21. Imaoka, S., Fujita, S. and Funae, Y. 1991. Age-dependent expression of cytochrome P-450s in rat liver. Biochim. Biophys Acta 1097: 187-192.

22. Ito, N., Shirai, T. and Fukushima, S. 1991. Medium-term bioassay for carcinogens using multiorgan models. Prog. Exp. Tumor. Res. 33: 41-57.

23. Ito, N., Tamano, S. and Shirai, T. 2003. A medium-term rat liver bioassay for rapid in vivo detection of carcinogenic potential of chemicals. Cancer Sci. 94: 3-8.

24. Ito, N., Tsuda, H., Tatematsu, M., Inoue, T., Tagawa, Y. Aoki, T., Uwagawa, S., Kagawa, M., Ogiso, T. and Masui, T. 1988. Enhancing effect of various hepatocarcinogens on induction of preneoplastic glutathione S-transferase placental form positive foci in rats--an approach for a new medium-term bioassay system. Carcinogenesis 9: 387-394.

25. Itoh, T., Moto, M., Takahashi, M., Sakai, H. and Mitsumori, K. 2006. Liver initiation activity of norfloxacin but not nalidixic acid, pipemidic acid, and ciprofloxacin on in vivo short-term liver initiation assay in rats. Toxicology 222: 240-246.

26. Kato, R. and Yamazoe, Y. 1992. Sex-specific cytochrome $\mathrm{P} 450$ as a cause of sex- and species-related differences in drug toxicity. Toxicol. Lett. 64-65 Spec No:661-667.

27. Kobayashi, K., Mutai, M., Goto, K., Inada, K., Tsukamoto, T., Nakanishi, H. and Tatematsu, M. 1997. Effects of carbon tetrachloride administration on initiation of liver cell foci by the non-hepatocarcinogens N-methyl-N'-nitro-N-nitrosoguanidine (MNNG) and benzo(a)pyrene (B(a)P). Cancer Lett. 118: 55-60.

28. Leclercq, I., Horsmans, Y. and Desager, J. 1998. Estimation of chlorzoxazone hydroxylase activity in liver microsomes and of the plasma pharmacokinetics of chlorzoxazone by the same high-performance liquid chromatographic method. J. Chromatogr. A. 828: 291-296.
29. Löw-Baselli, A., Hufnagl, K., Parzefall, W., Schulte-Hermann, R. and Grasl-Kraupp, B. 2000. Initiated rat hepatocytes in primary culture: a novel tool to study alterations in growth control during the first stage of carcinogenesis. Carcinogenesis 21: 79-86.

30. Moore, M., Nakagawa, K. and Ishikawa, T. 1988. Selection pressure and altered hepatocellular islands after a single injection of aflatoxin B1. Jpn. J. Cancer Res. 79: 187-194.

31. Moore, M., Nakagawa, K., Satoh, K., Ishikawa, T. and Sato, K. 1987. Single GST-P positive liver cells--putative initiated hepatocytes. Carcinogenesis 8: 483-486.

32. Ogiso, T., Tatematsu, M., Tamano, S., Tsuda, H. and Ito, N. 1985. Comparative effects of carcinogens on the induction of placental glutathione S-transferase-positive liver nodules in a short-term assay and of hepatocellular carcinomas in a longterm assay. Toxicol. Pathol. 13: 257-265.

33. Okamura, M., Sakai, H., Takahashi, N., Inagami, A., Tsukamoto, T., Yamamoto, M., Shirai, N., Iidaka, T., Yanai, T., Masegi, T. and Tatematsu, M. 2002. The effects of allyl alcohol-induced cell proliferation for detection of initiation activities of chemicals in rat liver. J. Toxicol. Pathol. 15: 95-102.

34. Omura, T. and Sato, R. 1964. The carbon monoxide-binding pigment of liver microsomes. I. Evidence for its hemoprotein nature. J. Biol. Chem. 239: 2370-2378.

35. Parton, J. and Garriott, M. 1997. An evaluation of micronucleus induction in bone marrow and in hepatocytes isolated from collagenase perfused liver or from formalin-fixed liver using four-week-old rats treated with known clastogens. Environ. Mol. Mutagen. 29: 379-385.

36. Pearce, R., McIntyre, C., Madan, A., Sanzgiri, U., Draper, A., Bullock, P., Cook, D., Burton, L., Latham, J., Nevins, C. and Parkinson, A. 1996. Effects of freezing, thawing, and storing human liver microsomes on cytochrome P450 activity. Arch. Biochem. Biophys. 331: 145-169.

37. Sakai, H., Tsukamoto, T., Yamamoto, M., Hirata, A., Inagami, A., Shirai, N., Iidaka, T., Yanai, T., Masegi, T. and Tatematsu, M. 2002a. Summation of initiation activities in the liver after partial hepatectomy. Cancer Lett. 176: 1-5.

38. Sakai, H., Tsukamoto, T., Yamamoto, M., Kobayashi, K., Yuasa, H., Imai, T., Yanai, T., Masegi, T. and Tatematsu, M. $2002 \mathrm{~b}$. Distinction of carcinogens from mutagens by induction of liver cell foci in a model for detection of initiation activity. Cancer Lett. 188: 33-38.

39. Sakai, H., Tsukamoto, T., Yamamoto, M., Shirai, N., Iidaka, T., Yanai, T., Masegi, T. and Tatematsu, M. 2001. Differential effects of partial hepatectomy and carbon tetrachloride administration on induction of liver cell foci in a model for detection of initiation activity. Jpn. J. Cancer Res. 92: 1018-1025.

40. Sakai, H., Tsukamoto, T., Yamamoto, M., Yanai, T., Masegi, T., Inada, K., Nakanishi, H. and Tatematsu, M. 2000. Summation of initiation activities of low doses of the non-hepatocarcinogen 1,2-dimethylhydrazine in the liver after carbon tetrachloride administration. Cancer Lett. 148: 59-63.

41. Sakai, H., Inagami, A., Hirata, A., Tsukamoto, T., Kobayashi, K., Degawa, M., Shirai, N., Iidaka, T., Yanai, T., Masegi, T. and Tatematsu, M. 2002c. The effects of D-galactosamine-or carbon tetrachloride-induced regeneration on induction of rat liver cell foci in a model for detection of initiation activities of chemicals. J. Toxicol. Pathol. 15: 13-18.

42. Schenkman, J., Thummel, K. and Favreau, L. 1989. Physiological and pathophysiological alterations in rat hepatic cytochrome P-450. Drug Metab. Rev. 20: 557-584.

43. Shimada, M., Murayama, N., Yamazoe, Y., Hashimoto, H., 
Ishikawa, H. and Kato, R. 1995. Age- and sex-related alterations of microsomal drug- and testosterone-oxidizing cytochrome P450 in Sprague-Dawley strain-derived dwarf rats. $J$. Pharmacol. Exp. Ther. 275: 972-977.

44. Sohn, O., Ishizaki, H., Yang, C. and Fiala, E. 1991. Metabolism of azoxymethane, methylazoxymethanol and Nnitrosodimethylamine by cytochrome P450IIE1. Carcinogenesis 12: 127-131.

45. Suzuki, H., Shirotori, T. and Hayashi, M. 2004. A liver micronucleus assay using young rats exposed to diethylnitrosamine: Methodological establishment and evaluation. Cytogenet. Genome Res. 104: 299-303.

46. Takasu, S., Tsukamoto, T., Hirata, A., Kawai, K., Toyoda, T., Ban, H., Sakai, H., Yanai, T., Masegi, T., Kasai, H. and Tatematsu, M. 2007. Lack of initiation activity of 4-oxo-2-hexenal, a peroxidation product generated from omega-3 polyunsaturated fatty acids, in an in vivo five-week liver assay. Asian Pac. J. Cancer Prev. 8: 372-374.

47. Tatematsu, M., Hasegawa, R., Imaida, K., Tsuda, H. and Ito, N. 1983. Survey of various chemicals for initiating and promoting activities in a short-term in vivo system based on generation of hyperplastic liver nodules in rats. Carcinogenesis 4 : 381-386.

48. Tatematsu, M., Mera, Y., Ito, N., Satoh, K. and Sato, K. 1985. Relative merits of immunohistochemical demonstrations of placental, A, B and C forms of glutathione S-transferase and histochemical demonstration of gamma-glutamyl transferase as markers of altered foci during liver carcinogenesis in rats. Carcinogenesis 6: 1621-1626.

49. Tatematsu, M., Miyata, Y., Mizutani, M., Hananouchi, M. and Hirose, M. 1977. Summation effect of N-butyl-n-4-hydroxybu- tylnitrosamine, N-4-5-nitro-2-furyl-2-thiazolyformamide, N-2fluoroenylacetamide, and 3,3'-dichlorobenzidine on urinary bladder carcinogenesis in rats. Gann 68: 193-202.

50. Tezuka, N., Tada, M., Kojima, M., Nakanishi, H., Mori, A. and Tatematsu, M. 1995. Effects of partial hepatectomy on initiation of liver cell foci by 4-nitroquinoline 1-oxide, a non-hepatocarcinogen, and generation of DNA adducts in rats. Cancer Lett. 89: 89-94.

51. Thomas, P., Bandiera, S., Maines, S., Ryan, D. and Levin, W. 1987. Regulation of cytochrome P-450j, a high-affinity Nnitrosodimethylamine demethylase, in rat hepatic microsomes. Biochemistry 26: 2280-2289.

52. Thurnherr, N., Deschner, E., Stonehill, E. and Lipkin, M. 1973. Induction of adenocarcinomas of the colon in mice by weekly injections of 1,2-dimethylhydrazine. Cancer Res. 33: 940-945.

53. Tsuda, H., Lee, G. and Farber, E. 1980. Induction of resistant hepatocytes as a new principle for a possible short-term in vivo test for carcinogens. Cancer Res. 40: 1157-1164.

54. van der Hoeven, T. and Coon, M. 1974. Preparation and properties of partially purified cytochrome P-450 and reduced nicotinamide adenine dinucleotide phosphate-cytochrome P-450 reductase from rabbit liver microsomes. J. Biol. Chem. 249: 6302-6310.

55. Ward, J., Yamamoto, R., Benjamin, T., Brown, C. and Weisburger, J. 1974. Experimentally induced cancer of the colon in rats and mice. J. Am. Vet. Med. Assoc. 164: 729-732.

56. Whalley, P., Bakes, D., Grime, K. and Weaver, R. 2001. Rapid high-performance liquid chromatographic method for the separation of hydroxylated testosterone metabolites. J. Chromatogr. B. Biomed. Sci. Appl. 760: 281-288 